\title{
Alterações ultra-estruturais musculares cardíacas induzidas pela idade no modelo animal
}

\author{
DR Castro ${ }^{1}$ \\ JC Ferreira ${ }^{2}$ \\ P Brum ${ }^{2}$
}

JA Duarte ${ }^{1}$

https://doi.org/10.5628/rpcd.09.02-03.141

\author{
${ }^{1}$ CIAFEL, Faculdade de Desporto \\ Universidade do Porto \\ Portugal \\ ${ }^{2}$ Escola de Educação Física e Esporte \\ Universidade de São Paulo \\ Brasil
}

\section{RESUMO}

Este trabalho teve por objectivo caracterizar, no modelo animal, as alterações ultra-estruturais musculares cardíacas associadas ao processo de envelhecimento biológico. A amostra foi constituída por 31 ratinhos machos, com 3 meses $(n=13)$ e com 7 meses $(n=18)$ de idade. Após sacrifício, a cada animal foi removido o coração com posterior processamento da parede ventricular esquerda para análise à microscopia electrónica de transmissão. Após digitalização das fotografias, foram quantificados o número, a frequência e as áreas, quer das mitocôndrias quer dos grânulos de lipofuscina/corpúsculos residuais. Os resultados evidenciaram uma maior heterogeneidade mitocondrial e maiores dimensões destes organelos, para os vários percentis estudados, nos animais de 7 meses. No que respeita à frequência mitocondrial por área celular, não se observaram diferenças significativas entre grupos ( 3 meses: $0,97 \pm 0,31$ vs 7 meses: $1,03 \pm 0,55 ; \mathrm{p}>0,05)$. Também não foram observadas alterações na densidade mitocondrial ( 3 meses: $42,10 \% \pm 9,64$ vs 7 meses: $45,17 \% \pm 18,38$; $p>0,05)$. Os grânulos de lipofuscina/corpúsculos residuais não aumentaram de dimensões nem alteraram a sua densidade celular com a idade ( 3 meses:

$0,35 \pm 0,51$ vs 7 meses: $0,67 \pm 1,12 ; p>0,05$ ); no entanto, a sua frequência, por área celular, foi significativamente maior nos animais de 7 meses ( 3 meses: 0,11 $\pm 0,21$ vs 7 meses: $0,16 \pm 0,16 ; \mathrm{p}<0,05)$. Dos resultados obtidos é possível concluir que são já evidentes nos animais de 3 meses alterações celulares degenerativas, as quais se agravam com a idade do animal. Os resultados permitem ainda concluir que a área das mitocôndrias cardíacas tende a aumentar com a idade, apesar da sua densidade celular se ter mantido constante.

Palavras-chave: envelhecimento, músculo cardíaco, mitocôndrias, grânulos de lipofuscina, corpúsculos residuais

\section{ABSTRACT \\ Age-induced cardiac muscle ultra-structural changes in the animal model}

The purpose of this work was to characterize, in the animal model, the cardiac muscle ultra-structural changes associated to biological aging process. The sample were 31 male mice, aged 3 months $(n=13)$ and 7 months $(n=18)$. After sacrifice, each animal was removed from the heart with subsequent processing of the left ventricular wall for analysis of transmission electron microscopy. The number, frequency and areas of the mitochondria and granules of lipofuscin / residual corpuscles were quantified by scanning of the obtained photographs. The results showed a higher mitochondrial heterogeneity and size of these organelles, for the various percentiles studied in animals of 7 months. Regarding the frequency of mitochondria by cellular area, there were no significant differences between groups ( 3 months: $0.97 \pm 0.31$ vs. 7 months: $1.03 \pm 0.55, p>0.05)$. Also there were no changes in mitochondrial density (3 months: $42.10 \% \pm 9.64$ vs. 7 months: $45.17 \%$ $\pm 18.38, p>0.05)$. The lipofuscin granules / residual corpuscles did not increase in size or changed their cellular density with age (3 months: $0.35 \pm 0.51$ vs. 7 months: $0.67 \pm 1.12, p>0.05$ ); however, their frequency, by cell area was significantly higher in animals of 7 months (3 months: $0.11 \pm 0.21$ vs. 7 months: $0.16 \pm 0.16, p$ $<0.05)$.

From results it is possible to conclude that are already evident degenerative cellular changes in 3 months aged animals, which worsen with aging. It can also be concluded that the area of cardiac mitochondria tends to increase with age, despite its cell density has remained fairly constant.

Key-words: aging, cardiac muscle, mitochondria, granules of lipofuscin, residual corpuscles 


\section{INTRODUÇÃO}

O envelhecimento é inerente a todos os seres vivos e expressa-se pela perda progressiva de funcionalidade máxima e pela diminuição da capacidade adaptativa orgânica, tornando os indivíduos mais susceptíveis à ocorrência de patologias e doenças e aumentando o risco de morte(30). Este, tornou-se um dos assuntos mais críticos para as sociedades industrializadas $(1,26$, 27) uma vez que, com o aumento da esperança média de vida, a idade média das populações tem vindo a aumentar e, com ela, também a prevalência das doenças associadas (36, 26). Estima-se que nos Estados Unidos, no ano 2050, existam cerca de 19 milhões de pessoas com idades superiores a 85 anos, o que representa o escalão etário de maior crescimento da sociedade americana ${ }^{(27)}$. Este crescimento explosivo do número de idosos acima dos 85 anos de idade terá um impacto dramático no futuro da prática da medicina ${ }^{(19)}$. A mesma situação repete-se nos países da Europa Ocidental onde 1/5 da população tem mais de 60 anos e, por cada indivíduo com idade até aos 15 anos, existem 9 com idade superior a 65 anos ${ }^{(24)}$. Intimamente relacionadas com o envelhecimento estão as doenças cardiovasculares, uma das principais preocupações da sociedade moderna. A idade, por si só, representa o principal factor de risco para a doença cardiovascular $(26,21)$, sendo o envelhecimento do coração acompanhado por mudanças progressivas, persistentes, potencialmente negativas e, teoricamente, irreversíveis ${ }^{(35)}$. Não obstante os grandes avanços da medicina, a doença cardiovascular permanece como a maior causa de mortalidade e morbilidade nas sociedades industrializadas (31, 26). A World Health Organization e a International Society of Hypertension referem que as doenças cardiovasculares são responsáveis por um terço das mortes em todo o mundo(16). Segundo Pugh e Wei(27), nos Estados Unidos, aproximadamente 1 milhão de pessoas por ano morrem de causas cardiovasculares, com enormes custos directos e indirectos de cuidados relacionados com doenças cardiovasculares nos idosos. De referir ainda, e segundo os mesmos autores, que as estimativas mostram que estes custos têm tendência para aumentar no decorrer das próximas décadas. No que concerne à Europa, e de acordo com a European Society of Cardiology, $49 \%$ das mortes ocorridas na Europa são consequência destas doenças(16), que representam ainda a principal causa de morte em adultos de meia-idade e de idosos na maior parte dos países europeus ${ }^{(4)}$.

Tendo em conta o exposto, as informações relativas às alterações funcionais e estruturais do sistema cardiovascular na ausência de doença com a idade são, desta forma, essenciais para a definição das características específicas do processo de envelhecimento cardiovascular que, como referido, é um dos factores de maior risco de doença cardiovascular(19). Estudos realizados revelam que com a idade há decréscimo gradual de elasticidade, da capacidade de estiramento e progressiva rigidez quer das paredes dos vasos quer das paredes cardíacas, estando o desenvolvimento da rigidez dos grandes vasos relacionado com o incremento de hipertensão sistólica isolada $(19,3,26)$. Paralelamente, a perda de elementos contrácteis do coração leva à perda da sua capacidade se adaptar a variações de pré e pós-carga, sobretudo se rápidas ${ }^{(29)}$. O coração torna-se ligeiramente aumentado de volume devido ao decréscimo de número de cardiomiócitos com consequente hipertrofia dos que

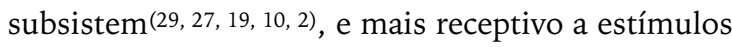
simpáticos (mas não parassimpáticos) ${ }^{(10)}$. No entanto, apesar de existirem, tal como se pode observar, bastantes estudos que documentam os efeitos do envelhecimento no coração, poucos são os que documentam as alterações histológicas do músculo cardíaco. Com efeito, grande parte dos estudos existentes foca as alterações bioquímicas e funcionais do sistema cardiovascular, em detrimento das alterações estruturais e ultra-estruturais. Para além disso, importa também referir que, no concerne os estudos realizados no âmbito do envelhecimento do sistema cardiovascular, estes salientam principalmente as alterações que ocorrem a nível vascular concentrando-se pouco no que ocorre a nível do coração. Contudo, é importante frisar que os estudos de carácter histológico são também decisivos para um melhor entendimento do envelhecimento a nível cardíaco, chamando, paralelamente, a atenção dos investigadores na área para futuros esforços de pesquisa. Neste sentido, o objectivo principal deste trabalho foi o de caracterizar, no modelo animal, as principais alterações ultra-estruturais do músculo cardíaco que ocorrem com o aumento da idade cronológica no modelo animal. 


\section{MATERIAL E MÉTODOS \\ Amostra}

Foram utilizados 31 ratinhos machos, da estirpe C57BL6, com 3 meses $(n=13$, peso de $26,2 \pm 2,08$ gramas) e 7 meses de idade $(n=18$, peso de $29,7 \pm$ 2,39 gramas), provenientes do Biotério Central da Faculdade de Medicina da USP Brasil. Os animais, alojados quatro em cada gaiola (Beira Mar SA, São Paulo, Brasil) tiveram livre acesso à água e à alimentação (Nuvital nutrientes SA, Curitiba, PR, Brasil), e foram mantidos à atmosfera normal, com uma temperatura de 21/24 graus centígrados e com uma variação cíclica de 12 horas luz /12 horas escuro.

\section{Procedimentos}

Todos os animais foram sacrificados por deslocamento cervical de acordo com os princípios éticos de experimentação animal adotados pelo Colégio Brasileiro de Experimentação Animal (COBEA, www.cobea.org.br). Após toracotomia, o coração foi removido e a parede externa do ventrículo esquerdo preparada para observação em microscopia electrónica de transmissão segundo as técnicas de rotina tradicionais. As peças foram seccionados em cubos de $1 \mathrm{~mm}$ de aresta e fixadas, durante 4 horas, em gluteraldeído $(2,5 \%$ em solução tampão de cacodilato de sódio a 2 M, pH 7.2 - 7.4). Foram posteriormente lavados em solução tampão, durante uma hora, pósfixados em tetróxido de ósmio a $2 \%$, durante 2 horas, e lavados novamente em solução tampão, durante trinta minutos. Em seguida, as amostras sofreram desidratação progressiva, sob a acção de concentrações crescentes de álcool etílico, durante 3 horas, e impregnação com epon durante 4 horas. $\mathrm{O}$ óxido de propileno foi o composto utilizado na transição desidratação/impregnação. O corte das amostras foi realizado após a fase de inclusão que durou 2 dias. Todos os procedimentos foram realizados a uma temperatura de $4^{\circ} \mathrm{C}$, com a excepção da fase de inclusão, que foi executada em estufa a uma temperatura de $60^{\circ} \mathrm{C}$. Dos blocos finais, foram realizados cortes ultra-finos, com uma espessura de $500 \AA$, destinados à observação em microscopia electrónica de transmissão. Estes cortes foram colocados em grelhas de cobre (300 Mesh) e contrastados com uma solução aquosa saturada de acetato de uranilo (durante 30 minutos) e com uma solução de citrato de chumbo (15 minutos), tendo-se procedido a lavagens no início e no final de cada um destes procedimentos.

Foi utilizado um microscópio electrónico de transmissão da marca Zeiss, modelo EM 10A, a uma voltagem de $60 \mathrm{KV}$.

Foram efectuadas fotografias das várias grelhas (4 grelhas por animal), com diferentes ampliações. As imagens foram digitalizadas com um scanner da marca Epson, modelo Perfection 4990 Photo, e posteriormente armazenadas no computador. Nas imagens digitalizadas, em função da ampliação usada, foi feita a correspondência da área da fotografia para $\mu \mathrm{m}^{2}$, sendo contabilizados o número de mitocôndrias e grânulos de lipofuscina e/ou corpúsculos residuais por $\mu \mathrm{m}^{2}$. Com a ajuda de um programa da morfometria (Image J. versão 1.36b, Wayne Rasband, National Institute of Health, USA), foram quantificadas as áreas das mitocondrias e dos grânulos de lipofuscina e/ou corpúsculos residuais. Foi ainda relativizada a área total das mitocôndrias com a área da célula fotografada (densidade mitocondrial) tendo o mesmo procedimento sido realizado para os grânulos de lipofuscina e/ou corpúsculos residuais presentes em cada fotografia. Para além desta análise quantitativa, foi ainda realizada uma análise qualitativa da estrutura global do tecido.

\section{Análise dos dados}

Para a análise quantitativa dos dados foi utilizado o programa SPSS (Statistical Package for the Social Sciences) - versão 14.0 para Microsoft Windows. Assim, e no caso dos dados referentes às áreas das mitocôndrias e grânulos de lipofuscina e/ou corpúsculos residuais, para testar a simetria da curva efectuou-se a divisão do desvio-padrão da Skewness pelo seu valor estatístico. Para testar a normalidade destas amostras foi utilizado o teste de KolmogrovSmirnov. Foi ainda realizada uma distribuição percentílica das áreas das mitocôndrias e uma distribuição quartílica das áreas dos grânulos de lipofuscina e/ou corpúsculos residuais. Para a realização das análises inferenciais recorreu-se ao teste de MannWhitney. Para a análise da simetria das curvas das densidades e frequências mitocondriais e de grânulos de lipofuscina e/ou corpúsculos residuais, foi efectuada a divisão do desvio-padrão da Skewness 

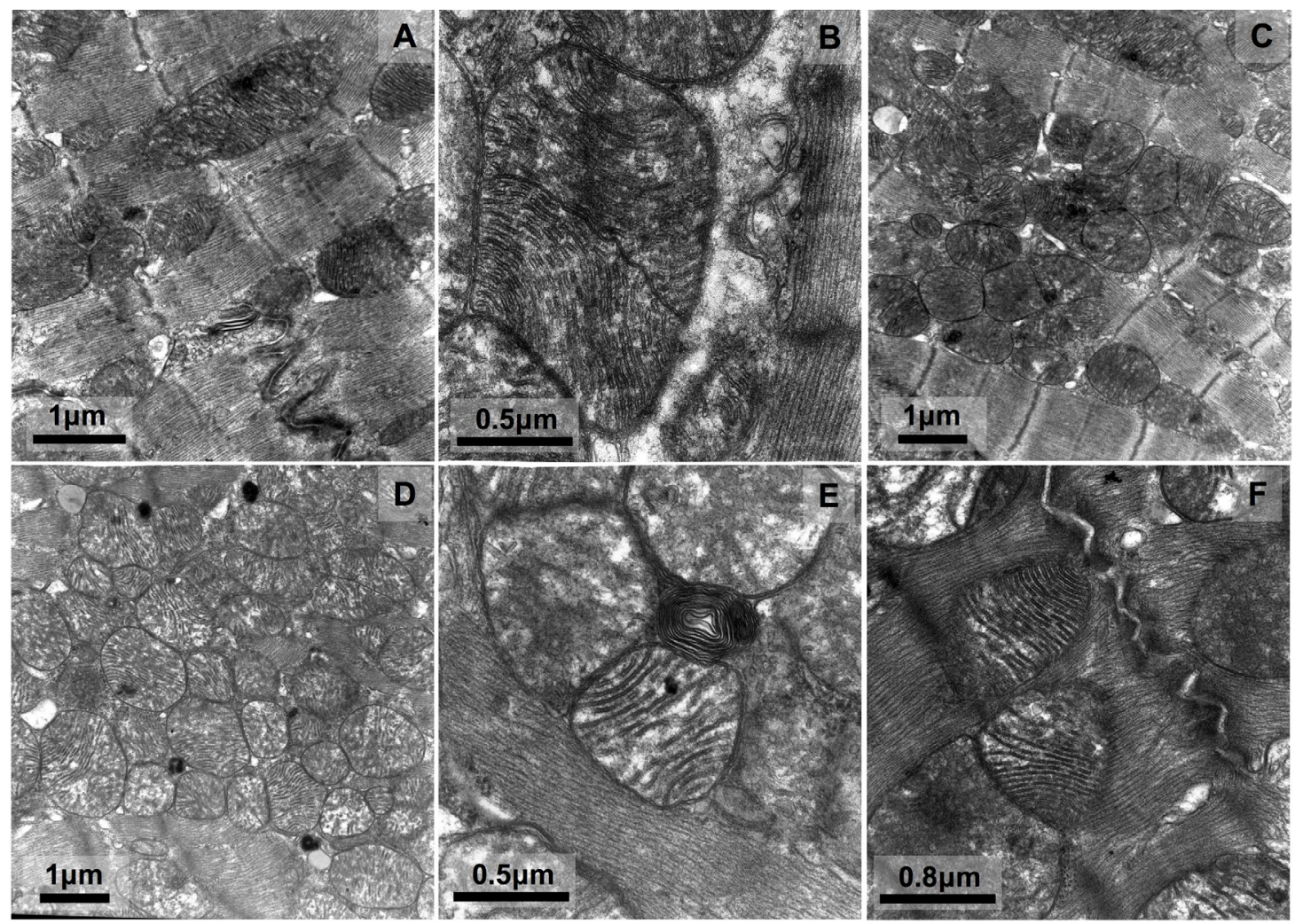

Figura 1. Fotografias de microscopia electrónica de diferentes secções do músculo cardíaco de animais de $3[\boldsymbol{A}, \boldsymbol{B}, \boldsymbol{C}$ ] e 7 meses de idade $[\boldsymbol{D}, \boldsymbol{E}$, F). A figura A mostra uma interdigitação celular dos discos intercalares, de estrutura aparentemente normal. Em $B$ pode ser observada uma mitocôndria em fissão e em C são ilustradas diversas mitocôndrias de dimensões variadas e estrutura homogénea, com cristas bem definidas; é ainda visível uma lipid droplet no canto superior esquerdo. Em D são evidentes inclusões de lipofuscina e mitocôndrias com grande heterogeneidade em tamanho, com cristas mal definidas em algumas delas, sendo também visível a dilatação do retículo bem como a como a existência de lipid droplets. Em $\mathcal{E}$ pode ser observada uma figura de mielina e duas mitocôndrias com cristas menos definidas, em contraste com uma mitocôndria com as cristas melhor evidenciadas. A figura $F$ ilustra um disco intercalar com uma reduzida interdigitação celular assim como duas mitocôndrias com cristas melhor definidas comparativamente às restantes.

pelo seu valor estatístico. Para testar a normalidade destas amostras foi utilizado o teste de ShapiroWilke. Para a análise inferencial destes dados recorreu-se, no caso dos dados relativos às mitocôndrias, ao t-test para medidas independentes; no caso dos grânulos de lipofuscina foi utilizado o teste nãoparamétrico de Man-Whitney. Na aplicação destes testes foi considerado um índice de significância de $\alpha=0,05$.

\section{RESULTADOS}

\section{Análise qualitativa}

A análise ultra-estrutural do músculo cardíaco dos animais de 3 meses (Figuras 1A, 1B e 1C) eviden- ciou um padrão miofibrilar estriado aparentemente normal, sendo evidentes, em algumas células, alterações focais do retículo sarcoplasmático e também, de forma focal, depósitos de lípidos ("lipid droplets"); foram ainda observados nestes animais, embora muito raramente, grânulos de lipofuscina e/ou corpúsculos residuais. As mitocôndrias apresentavam dimensões heterogéneas, de estrutura homogénea, com cristas bem definidas, tendo esporadicamente sido observadas mitocôndrias em fissão. A interdigitação celular dos discos intercalares, foi também analisada, apresentando uma estrutura e dimensões aparentemente normais.

A análise ultra estrutural do músculo cardíaco dos 
Tabela 1. Valores médios \pm desvios-padrão e amplitude de variação das áreas (em $\mu \mathrm{m} 2$ ) das mitocôndrias e dos grânulos de lipofuscina e/ou corpúsculos residuais $[G L / C R$ ] nos dois grupos de animais.

\begin{tabular}{lcc}
\hline Grupo & 3 meses & 7 meses \\
\hline Áreas das mitocôndrias $(\mu \mathrm{m} 2)$ & $0,47 \pm 0,33$ & $0,62 \pm 0,46$ \\
\hline Amplitude de variação das áreas mitocondriais $(\mu \mathrm{m} 2)$ & $0,02-3,04$ & $0,02-3,88$ \\
\hline Áreas dos GL/CR $(\mu \mathrm{m} 2)$ & $0,04 \pm 0,06$ & $0,035 \pm 0,05$ \\
\hline Amplitude de variação das áreas dos GL/CR $(\mu \mathrm{m} 2)$ & $0,002-0,447$ & $0,002-0,444$
\end{tabular}

animais com 7 meses (Figuras 1E, 1F e 1G) evidenciou cardiomiócitos com um padrão miofibrilar estriado regular. À semelhança dos animais de 3 meses, foi também observada neste grupo uma dilatação do retículo, embora de carácter mais difuso. Foram observados numerosos grânulos de lipofuscina em grande parte das células observadas, assim como corpúsculos residuais (figuras de mielina). Também neste grupo foi observada uma grande heterogeneidade nas mitocôndrias, tanto em termos de dimensão como na sua estrutura. De referir que o primeiro grupo (3 meses) apresentava uma estrutura destes organelos mais homogénea. Foram observadas mitocôndrias mais claras contrastando com outras mais electrodensas, mitocôndrias com mais cristas e mitocôndrias com cristas mais indefinidas. Também no espaço intersticial, à semelhança do encontrado nos ratos de 3 meses, não foram encontradas alterações dignas de registo, tendo os capilares uma estrutura aparentemente normal.

\section{Análise quantitativa}

A Tabela 1 apresenta os valores médios absolutos e respectivos desvios-padrão das áreas das mitocôndrias e grânulos de lipofuscina e/ou corpúsculos residuais, bem como as suas respectivas amplitudes de variação, medidos em $\mu \mathrm{m}^{2}$, para ambos os grupos. Pela análise da Tabela 2 constata-se que a distribuição realizada para as áreas das mitocôndrias apresenta diferenças significativas entre grupos em todos os percentis. A Figura 2 ilustra a variação com a idade dos vários percentis de distribuição das áreas mitocondriais. No referente às áreas dos grânulos de lipofuscina e/ou corpúsculos residuais verificou-se que apenas o quartil 50 apresenta diferenças significativas entre grupos (Tabela 3 ).
Tabela 2. Distribuição percentílica das áreas mitocondriais ( $\mu \mathrm{m} 2$ ] nos dois grupos de animais.

\begin{tabular}{lccccc}
\hline Percentil & 10 & 25 & 50 & 75 & 90 \\
\hline 3 meses & 0,125 & 0,220 & 0,408 & 0,0647 & 0,894 \\
\hline 7 meses & 0,162 & 0,296 & 0,490 & 0,841 & 1,255 \\
\hline$p$ & 0,000 & 0,000 & 0,000 & 0,000 & 0,000 \\
\hline
\end{tabular}

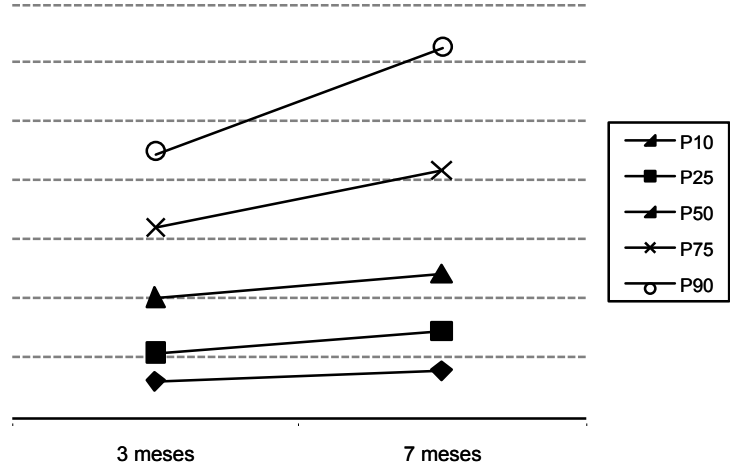

Figura 2. Variações com a idade dos vários percentis de distribuição das áreas mitocondriais.

Tabela 3. Distribuição quartílica das áreas dos grânulos de lipofuscina e/ou corpúsculos residuais ( $\mu \mathrm{m} 2$ ) nos dois grupos de animais.

\begin{tabular}{lccc}
\hline Quartil & 25 & 50 & 75 \\
\hline 3 meses & 0,012 & 0,021 & 0,042 \\
\hline 7 meses & 0,012 & 0,018 & 0,042 \\
\hline$p$ & 0,428 & 0,007 & 0,053 \\
\hline
\end{tabular}

A Figura 3 ilustra a variação com a idade dos vários quartis de distribuição das áreas dos grânulos de lipofuscina e/ou corpúsculos residuais. 
Tabela 4 - Valores médios \pm desvios-padrão das densidades e das frequências celulares de mitocondrias

e de grânulos de lipofuscina e/ou corpúsculos residuais [GL/CR], para ambos os grupos.

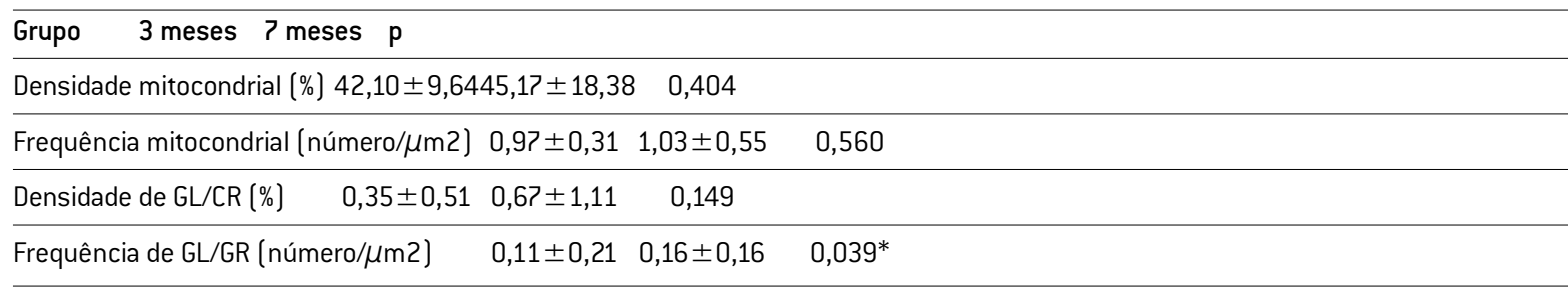

* Valor de prova com significado estatístico encontrado na aplicação do teste de Mann-Whitney.

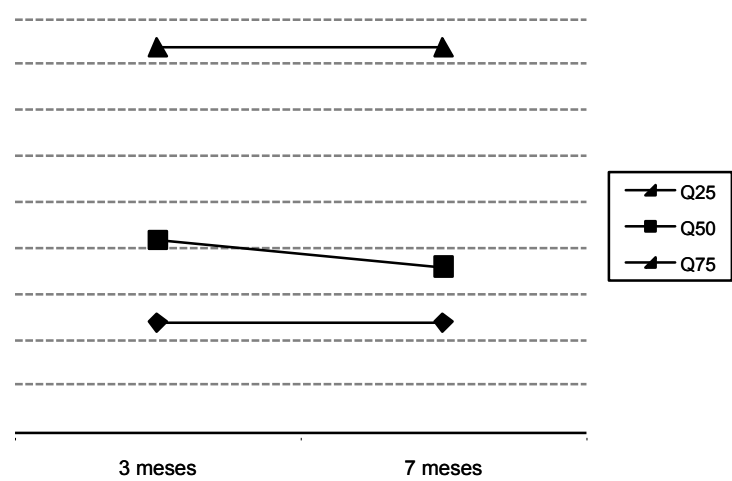

Figura 3. Variações com a idade dos vários quartis de distribuição das áreas dos grânulos de lipofuscina e/ou corpúsculos residuais.

A tabela 4 apresenta os valores médios absolutos e respectivos desvios-padrão das densidades e frequências das mitocôndrias e depósitos de lipofuscina e/ou corpúsculos residuais, para ambos os escalões etários. Não existem diferenças significativas entre as médias das densidades e frequências mitocondriais entre grupos. A comparação entre grupos da frequência de depósitos de lipofuscina e/ou corpúsculos residuais demonstra que estes apresentam diferenças estatisticamente significativas. Não foram observadas diferenças estatisticamente significativas entre grupos no caso da densidade de lipofuscina e/ou corpúsculos residuais.

\section{DISCUSSÃO}

Dos resultados encontrados foi possível observar que, talvez devido a uma baixa capacidade regenerativa, existiam já nos animais jovens indicadores característicos do processo degenerativo e que estes se agravavam nos animais adultos. Estes dados estão de acordo com o conceito de que o envelhecimento de organismos multicelulares é mais evidente em órgãos ou tecidos constituídos maioritariamente por células pós-mitóticas, tais como os miócitos cardía$\cos (32,34)$. Devido à sua baixa capacidade regenerativa, é natural que as marcas deixadas pelas agressões diárias a que as células se sujeitam durante a sua actividade subsistam no tempo. Desta forma, não será de estranhar que animais relativamente jovens apresentem já estas marcas da passagem do tempo, sendo as alterações mitocondriais e a acumulação de lipofuscina as alterações que se destacam com mais proeminência nestas células(6, 34).

É também possível que as células pós-mitóticas possam ser mais susceptíveis aos danos cumulativos das EROs devido à incapacidade de se auto-substituir. Com efeito, o coração passa, aparentemente, por uma redução de número de células nobres com o passar do tempo, podendo esta redução de número ser devida à ocorrência de morte celular por apoptose como consequência de danos irreversíveis nas células(15). Esta incapacidade de substituição das células que contém DNA mitocondrial com mutações, em tecidos pós-mitóticos, por células saudáveis, pode também explicar a maior incidência de mutações no DNA mitocondrial em tecidos pós-mitotóticos versus tecidos mitóticamente activos ${ }^{(15)}$. Assim, esta baixa capacidade regenerativa das células pós-mitóticas pode explicar a razão de existirem já marcas de degenerescência celular ratos jovens e de estas aumentarem nos animais com 7 meses de idade.

Olhando para os valores das áreas mitocondriais, em termos médios, podemos constatar que a área média destes organelos foi maior aos 7 meses de idade e que, tendo em conta o seu desvio-padrão, este grupo 
apresenta uma grande amplitude de variação. No entanto, e pelo facto deste parâmetro não apresentar uma distribuição normal, recorremos à análise da sua distribuição percentílica. Foi possível observar que existe uma grande heterogeneidade em termos de dimensões da população mitocondrial nos animais adultos, estando também descrito, em tecidos com células pós-mitóticas de animais senescentes, uma extrema variabilidade no tamanho e formas das mitocôndrias (33, 36). Esta heterogeneidade pode ser devida às diferenças de idades entre mitocôndrias. De facto, as mitocôndrias das células pós-mitóticas envelhecidas tendem a apresentar um potencial electro-químico diminuído e a produzir menos ATP do que as mitocôndrias de células mais jovens, devido a deficiências causadas na cadeia respiratória, motivadas por mutações no DNA mitocondrial pela provável acção das ERO(12). Segundo Hood et al.(14), é possível que este distúrbio metabólico esteja envolvido no despoletar do aumento progressivo do conteúdo mitocondrial, de forma a compensar o decréscimo no ATP. Desta forma, é natural encontrarmos nas células dos animais adultos mitocôndrias jovens acabadas de formar. Julga-se ainda que esta heterogeneidade de dimensões mitocondriais resulta de uma capacidade de fissão alterada das mitocôndrias com dano oxidativo e de deficiências na autofagia das mitocôndrias "gigantes", observando-se que, enquanto estas persistem nas células, e perdem a sua função respiratória, existe um aumento compensatório de mitocôndrias pequenas, acabadas de ser geradas $(8,32)$. As maiores dimensões mitocondriais nos vários percentis estudados encontradas nos animais de 7 meses, apresentando as dimensões extremas neste grupo de animais, podem também ser explicadas quer pela diminuição da sua capacidade de divisão quer pela diminuição da capacidade de autofagocitose dos cardiomiócitos, sugerindo que a morfologia mitocondrial está longe de ser estática. De facto, as mitocôndrias das células pós-mitóticas envelhecidas são geralmente aumentadas, muitas vezes ao ponto de serem chamadas "gigantes", e demonstram danos estruturais que variam desde o edema da matriz a uma quase completa destruição dos componentes mitocondriais (7). O edema da matriz mitocondrial está causalmente associado à perda do potencial electroquímico membranar por perturbação da integridade da membrana interna mitocondrial(11). Considera-se que estas alterações possam derivar dos efeitos danosos do stress oxidativo decorrentes da própria funcionalidade mitocondrial $(6,13,34,7)$. De facto, para além destes organelos serem os responsáveis pela maior porção de ERO produzido a nível intracelular(15), é importante frisar que o DNA mitocondrial, não estando protegido por histonas e sendo reparado de forma menos eficiente, é mais sujeito a mutações quando comparado ao DNA nuclear(23). Não obstante estes factores, a reciclagem mitocondrial deveria permitir a eliminação das mitocôndrias danificadas por autofagocitose e a sua substituição através da replicação de mitocôndrias normais. Uma vez que existe, de facto, uma acumulação de mitocôndrias danificadas nos miócitos cardíacos, subentende-se que a reciclagem autofágica está longe de ser perfeita.

Uma das grandes teorias do envelhecimento assenta no pressuposto de que as mutações no DNA mitocondrial e o dano oxidativo possam contribuir para o processo de envelhecimento biológico. Danos no DNA mitocondrial podem efectivamente transformar o simbionte num parasita(17). Especula-se que as mutações que se acumulam com a idade possam levar a uma produção de energia deficiente bem como ao acréscimo de produção de ERO, resultando em dano celular(12, 5). O stress oxidativo e o dano oxidativo podem, pois, desempenhar um papel crítico no processo de envelhecimento. Na última década, evidências abundantes sugerem que o ritmo de produção de ERO aumenta com a idade e que, por outro lado, a eficácia da degradação das biomoléculas modificadas pelo dano oxidativo diminui(20). A teoria do envelhecimento mitocondrial considera a acumulação de mitocôndrias deficientes como o mecanismo central responsável pelo processo de envelhecimento $(18,20,17)$. Esta ideia encontra muitos apoiantes $(25,28,22,33)$ e coloca a acumulação de mitocôndrias danificadas com a idade nas células e tecidos, como uma grande contribuição para um declínio funcional gradual com a idade.

No referente à densidade mitocondrial, aparentemente esta não tende a aumentar com a idade. No entanto, nos animais adultos encontrámos uma maior diversidade deste parâmetro entre células, existindo células com grandes e outras com baixas 
densidades mitocondriais. Podemos desta forma concluir que as células não sejam todas iguais nem reajam de igual forma à passagem do tempo, sendo provável que existam células mais capazes que outras.

Os nossos resultados revelam ainda que a frequência mitocondrial se mantém com a idade cronológica. Desta forma, e uma vez que não se regista um aumento da densidade e frequência mitocondrial com a idade, e que, no entanto, estas tendem a aumentar significativamente de volume, podemos especular que ocorre, com o processo de envelhecimento, um aumento das áreas celulares (hipertrofia dos cardiomiócitos).

Relativamente às áreas dos grânulos de lipofuscina e/ ou corpúsculos residuais, aparentemente não aumentam com a idade, registando-se até, pelo contrário, uma diminuição no quartil 50. No entanto, a sua frequência celular aumenta com a idade pois, à medida que o tempo passa, maior número destas degenerações se vão acumulando nas células. Os nossos resultados sugerem que, embora haja formação continuada de moléculas de lipofuscina em cada célula, estas não parecem ter tendência a fundir-se às já existentes na célula. É ainda possível que, devido a uma capacidade diminuída da eficácia de degradação das biomoléculas modificadas pelo dano oxidativo nas células envelhecidas, estes grânulos derivem de mitocôndrias danificadas que não conseguiram ser devidamente autofagocitadas, explicando desta forma o aumento significativo da frequência celular de grânulos de lipofucsina e/ou corpos residuais observado nos animais adultos. Foi ainda observado que nos animais mais velhos existe uma grande amplitude de variação entre células das densidades dos grânulos de lipofuscina e/ ou corpúsculos residuais uma vez que os desvios padrão neste grupo são mais elevados. Sendo a lipofuscina um produto residual da peroxidação de lipoproteínas celulares, não degradável, os depósitos deste pigmento aumentam em número com a idade, ocupando uma porção cada vez maior do espaço intracelular $(8,27)$.

\section{CONCLUSÕES}

Os resultados obtidos permitem concluir que os animais jovens evidenciam já marcas características do processo de envelhecimento, tendendo estas a se agravar nos animais adultos. Para além disso, parece existir uma grande heterogeneidade em termos de dimensões da população mitocondrial, especialmente nos animais adultos. Os valores das áreas mitocondriais, em termos médios, foram maiores nos animais adultos, aumentando significativamente com a idade em todos os percentis estudados, sendo as mitocôndrias mais heterogéneas e de dimensões extremas nos animais adultos, sugerindo os nossos resultados que a morfologia mitocondrial está longe de ser estática. No entanto, a densidade mitocondrial, aparentemente, não parece tender a aumentar nos animais com 7 meses. No que respeita às áreas dos grânulos de lipofuscina e/ ou corpúsculos residuais, estes não aumentam com o tempo em termos de dimensões mas a sua frequência celular parece aumentar com a idade.

\author{
CORRESPONDÊNCIA \\ José Alberto Duarte \\ CIAFEL, FADEUP \\ Rua Dr. Plácido Costa 91 \\ 4200-450 Porto, Portugal \\ Tel: +351 225074784 \\ Fax: +351 225500689 \\ E-mail: jarduarte@fade.up.pt
}




\section{REFERÊNCIAS BIBLIOGRÁFICAS}

1. Andrawes W, Bussy C, Belmin, J. (2005). Prevention of cardiovascular events in elderly people. Drugs Aging, 22 (10): 859-876

2. Anversa P, Rota M, Urbaneck K, Hosoda T, Sonnenblick EH, Leri A, Kajustra J, Bolli R. (2005). Myocardial aging. A stem cell problem. Basic Res Cardiol, 100: 482-493

3. Aronson D (2004). Pharmacological prevention of cardiovascular aging - Targeting the Mailard reaction. $\mathrm{Br} \mathrm{J}$ Pharmacol, 142: 1055-1058

4. Backer GD, Ambrosioni E, Broch-Johnsen K, Brotons C, Cifkova R, Dallongeville J, Ebrahim S, Faergeman O, Graham I, Mancia G, Cats VM, Orth-Gomér K, Perk P, Pyörälä K, Rodicio JL, Sans S, Sansoy V, Sechtem U, Silber S, Thomsen T, Wood D (2003). European guidelines on cardiovascular disease prevention in clinical practise. Third joint task force of european and other societies on cardiovascular disease prevention in clinical practise. Eur $J$ Cardiovasc Prev Rehabil, 10 (Suppl 1): S1-S78

5. Beal MF (2005). Mitochondria take center stage in aging and neurodegenaration. Ann Neurol, 58: 495-505

6. Beckman KB, Ames BN (1998). The free radical theory of aging matures. Physiol Rev, 78: 547-581

7. Brookes PS, Yoon Y, Robotham JL, Anders MW, Sheu S-S (2004). Calcium, ATP, ROS: a mitochondrial love-hate triangle. Am J Physiol, 287, C817-C833

8. Brunk T, Terman A (2002). The mithocondrial-lysosomal axis theory of aging. Acumulation of damaged mitochondria as a result of imperfect autophagocytosis. Eur J Biochem, 269: 1996-2002

9. Cristofalo VJ, Gerhard GS, Pignolo RJ (1994). Molecular biology of aging. Surg Clin North Am, 74: 1-21

10. Ferrari FU, Radaelli A, Centola M (2003). Aging and the cardiovascular system. J Appl Physiol, 95: 2591-2597

11. Frank S, Gaume B, Bergmann-Leitner ES, Leitner WW, Robert EG, Catez F, Smith CL, Youle RJ (2001). The role of dynamin protein 1, a mediator of mitochondrial fission, in apoptosis. Dev Cell, 1: 515-525

12. Hagen TM, Moreu R, Suh JH, Visioli F (2002). Mitochondrial decay in the aging rat heart. Evidence for improvement by dietary supplementation with Acetyl-LCarnitine and/or Lipoic Acid. Ann N Y Acad Sci, 959: 491507

13. HipKiss AR (2003). Errors, mitochondrial dysfunction and ageing. Biogerontol, 4: 397-400

14. Hood DA, Adhihetty PJ, Colavechia M, Gordon JW, Irrcher I, Joseph A-M, Lowe ST, Rungi AA (2003). Mitochondrial biogenesis and the role of the protein import pathway. Medicine and Science in Sports \& Exercise, 35(1): 86-94

15. Johnson FB, Sinclair DA, Guarente L (1999). Molecular biology of aging. Cell, 96: 291-302

16. Kaplan N, Mendis S, et al. (2003). 2003 World Health Organization / International Society of Hipertension statement on management of Hypertension. J Hypertens, 21: $1983-1992$

17. Kowland A, Jendrach M, Pohl S, Bereither-Hanh J, Hammerstein P (2005). On the relevance of mitochondrial fusions for the accumulation of mitochondrial deletion mutants: A modelling study. Aging Cell, 4: 273-283

18. Kowland A, Kirkwood TBL (2000). Acccumulation of defective mitochondria trough delayed degradation of damaged organelles and its possible role in ageing of postmitotic and dividing cells. $J$ Theor Biol, 202: 145-160

19. Lakatta EG, Sollott SJ (2002). The 'heart-break' of older age. Mol Interv, 2 (7): 431-446

20. Lee H-C, Wei Y-H (2001). Mitochondrial alterations, cellular response to oxidative stress and defective degradation of proteins in aging. Biogerontol, 2: 23-244

21. Li S-Y, Du M, Dolence EK, Fang CX, Mayer GE, Ceylan-Isik AF, LaCour KH, Yang X, Wilbert CJ, Sreejayan N, Ren J (2005). Aging induces cardiac diastolic dysfunction, oxidative stress, accumulation of advanced glycation end products and protein modification. Aging Cell, 4: 57-64

22. Linnane AW, Marzuki S, Ozawa T, Tanaka M (1989). Mitichondrial DNA mutations as an important contributor to ageing and degenerative diseases. Lancet, 1(8639): 642645

23. Logan DC (2006). The mitocondrial compartment. Journal of Experimental Botany, 57 (6): 225-243

24. Marques A (1993). Actividade física e saúde na terceira idade, in: Physical Activity and Health in the Eldery Proceedings of the 1st conference of EGREPA; Oeiras; Portugal, 26-30, October.

25. Miquel J (1980). Mitochondrial role in cell ageing. Exp Gerontol, 15(6): 575-591

26. Pepe S, Lakatta EG (2005). Aging heart and vessels : Masters of adaptation and survival. Cardiovasc Res, 66: 190193

27. Pugh KG, Wei JY (2001). Clinical implications of physiological changes in the aging heart. Drugs Aging, 18 (4): 263 276

28. Richter C (1989). Do mitochondrial DNA fragments promote cancer and aging?. Febs Letters, 241(1-2): 1-5

29. Robert L (1994). O Envelhecimento. Publicações Instituto Piaget.

30. Spirduso W (1995). Physical Dimensions of Aging. Champaign: Human Kinetics.

31. Sussman M, Anversa P (2004). Myocardial aging and senescence: Where have the stem cells gone?. Annu Rev Physiol, 66: 29-48

32. Szibor M, Holtz J (2003). Mitochondrial ageing. Basic Res Cardiol, 98: 210-218

33. Terman T, Brunk UT (2005). Autophagy in cardiac myocyte homeostasis, aging, and pathology. Cardiovasc Res, 68, 355365

34. Terman A, Dalen H, Eaton JW, Neuzil J, Brunk UT (2003). Mitochondrial recycling and aging myocytes: the role of autophagocytosis. Exp Gerontol, 38: 863-876

35. Trifunovic A, Wredenberg A, Falkenberg M, Spelbrink JN, Rovio AT, Bruder CE, Bohlooly M, Gldlof S, Oldfors A, Wilbon R, Tornel J, Jacobs HT, Larsson N-G (2004). Premature aging in mice expressing defective mitochondrial DNA polymerase. Nature, 429: 417-423

36. Weinert BT, Timiras PS (2003). Physiology of aging: Theories of aging. J Appl Physiol, 95: 1706-1716 